\title{
SÍNTESE DA EVOLUÇÃO DOS PRINCIPAIS INDICADORES SÓCIO ECONÔMICOS UTILIZADOS COMO MEDIDA DA DESIGUALDADE SOCIAL NO BRASIL ENTRE OS ANOS 2000 E 2015
}

\author{
Paula Margarita Andrea Cares Bustamante \\ Universidade Estadual de Montes Claros
}

\begin{abstract}
RESUMO
O artigo objetiva apresentar os principais conceitos relacionados ao desenvolvimento e verificar como isso tem se dado no Brasil a partir do ano 2000. Especificamente o trabalho objetiva identificar o comportamento dos indicadores socioeconômicos no Brasil a partir de 2000. A metodologia utilizada no trabalho será a revisão bibliográfica com base nos textos de Souza (2012) e Paulani; Braga (2007) que apresentam as teorias de desenvolvimento econômico, Jannuzzi (2012) trabalha o conceito de indicadores sociais e, Neri e Souza (2012); Oxfam (2017) apresentam o comportamento dos principais índices sociais no Brasil ao longo da década 2000 e descrevem a importância e limitação dos indicadores sociais. Constatou-se que o crescimento econômico no período analisado, junto com a redução das desigualdades de renda, favoreceu a melhoria das condições de vida da população brasileira, apesar de manter o status quo no que tange a estrutura social desigual do país.
\end{abstract}

Palavras-chave: Desigualdade social. Indicadores sociais. Indicadores econômicos.

\section{SUMMARY OF THE EVOLUTION OF MAIN ECONOMIC SOCIAL INDICATORS USED AS A MEASURE FOR SOCIAL INEQUALITY IN BRAZIL BETWEEN 2000 AND 2015}

\begin{abstract}
The article aims to present the main concepts related to development and to verify how this has occurred in Brazil since the year 2000. Specifically the work aims to identify the behavior of socioeconomic indicators in Brazil from 2000. The methodology used in the research will be the review bibliography based on texts by Souza (2012) and Paulani; Braga (2007) presenting theories of economic development, Jannuzzi (2012) works on the concept of social indicators and, Neri and Souza (2012); Oxfam (2017) present the behavior of the main social indices in Brazil throughout the decade of 2000 and describe the importance and limitation of social indicators. It was found that economic growth in the period analyzed, together with the reduction of income inequalities, favored the improvement of the living conditions of the Brazilian population, despite maintaining the status quo regarding the unequal social structure of the country.
\end{abstract}

Keywords: Social inequality. Social indicators. Economic indicators. 


\section{INTRODUÇÃO}

No período entre 2000 e 2015 a Brasil vivenciou um momento de crescimento econômico, geração de emprego e renda, aumento dos gastos sociais, valorização do salário mínimo e a redução da pobreza. De acordo como IBGE (2015), entre 2002 e 2013, o salário mínimo nacional teve um aumento real de 70,49\%, impactando diretamente no poder de compra e qualidade de vida de cerca de 11 milhões de aposentados que recebem um salário mínimo. Quanto ao emprego, entre 2003 e 2010, houve um crescimento de mais de 53\% de novos postos formais de empregos.

Em grande medida, a melhoria dos indicadores socioeconômicos no país, entre o ano 2000 e 2015, resultaram das políticas adotadas pelos governos do Partido dos Trabalhadores - PT, do Presidente Luís Inácio Lula da Silva (2003/2010) e da Presidente Dilma Rousseff (2011/2016), que vislumbraram por meio de políticas públicas e sociais, o desenvolvimento, a transformação e reversão da tendência estrutural concentradora de renda no país. Cabe ressaltar que, devido ao golpe político/parlamentar/jurídico/midiático de 2016 a Presidente Dilma Rousseff não pôde terminar seu mandato e, esse golpe político contra a democracia favorece desde então a retomada a concentração de renda e do aumento da desigualdade social (GONÇALVEZ, 2012; MITIDIERO JUNIOR, M. A.; FELICIANO, C. A., 2018).

À luz dessas considerações este artigo objetiva apresentar os principais conceitos relacionados ao desenvolvimento e verificar como isso tem se dado no Brasil a partir do ano 2000. Especificamente, o trabalho objetiva identificar o comportamento dos indicadores socioeconômicos no Brasil a partir de 2000.

A metodologia utilizada na pesquisa será a revisão bibliográfica com base nos textos de SOUZA (2012) e PAULANI; BRAGA (2007) que apresentam as teorias de desenvolvimento econômico de diferentes correntes de pensamento, JANNUZZI (2012) trabalha o conceito de indicadores sociais e, Neri e Souza (2012); OXFAM (2017) analisam o comportamento dos principais índices sociais no Brasil ao longo da década 2000 e descrevem a importância e limitação dos indicadores sociais.

Os dados referentes ao Produto Interno Bruto (PIB), Índice de Desenvolvimento Humano (IDH), o Coeficiente Gini e a Linha de Pobreza foram extraídos de sítios na internet tais como Instituto Brasileiro de Geografia Estatística (IBGE), Instituto de Pesquisa Econômica Aplicada (IPEA) e Programa das Nações Unidas (PNUD) em prol do Desenvolvimento que busca analisar o desenvolvimento em abrangência mundial, entre outros.

Além desta introdução, na próxima seção serão apresentadas as principais teorias do desenvolvimento socioeconômico, conceitos e limitações. Na seção seguinte serão conceituadas as 
principais variáveis que medem a desigualdade social. Posteriormente são apresentadas as principais conquistas sociais alcançadas pela sociedade brasileira nos ultimas quinze anos. Finalmente serão apresentadas as considerações finais.

\section{AS PRINCIPAIS TEORIAS DO DESENVOLVIMENTO SOCIOECONÔMICO: CONCEITOS E LIMITAÇÕES}

Apesar do termo 'desenvolvimento econômico' ter ganhado destaque somente em meados do século XX, desde o século XVIII na físiocracia existia uma preocupação em tentar mensurar de forma coerente as relações econômicas em determinado período de tempo, cabe salientar que o 'pano de fundo' desse pensamento sempre esteve associado à ideia de progresso, produção industrial, padrão de consumo e ao estilo de vida dos países da Europa Ocidental.

Autores da chamada escola econômica clássica como Adam Smith (1723-1790), David Ricardo (1772-1823), Jonh Stuart Mill (1806-1873) e Jean Batiste Say (1767-1832) debruçaram-se em temas como crescimento econômico e a repartição do produto social, no entanto, estes autores limitavam-se em afirmar que "... a liberdade de troca e transação é ela própria uma parte essencial das liberdades básicas que as pessoas têm razão para valorizar" (Smith apud Sen, 2010, p.20), ou seja, para os clássicos, crescimento econômico estava relacionado somente à capacidade de acumulação de riqueza.

Durante o século XIX a Europa vivenciou as benesses da revolução industrial e observava o 'progresso da humanidade', no entanto o incipiente sistema capitalista começou a passar por sucessivas crises, com ciclos cada vez mais curto e mais profundos, que culminaram com na Primeira Guerra Mundial que, segundo Ortega (2008, p.23), 'colocou uma pá de cal' na visão otimista de progresso retilíneo do capitalismo.

Nesse contexto, em 1930 ganha destaque a obra de Keynes (1883-1946) intitulada de "A teoria geral do emprego, do juro e da moeda", pois desenvolve a literatura sobre sistema de contas nacionais onde passa a ser possível medir em nível agregado a riqueza dos países, o que possibilitou a ‘comparação' entre países com diferentes graus e estágios de desenvolvimento. Sendo assim:

(...) a revolução keynesiana, como costuma ser chamada a intervenção de Keynes no debate acadêmico, conferiu aos economistas a capacidade de verificar o comportamento e a evolução da economia de um país numa dimensão sistêmica, ou seja, não só medindo a produção, renda e consumo, mas fazendo isso de modo a perceber exatamente a relação entre esses agregados e a lógica do sistema econômico como um todo (PAULANI; BRAGA, 2007, p. 4).

Ainda de acordo com Paulani e Braga (2007, p.29): 
(...) a necessidade de estabelecer comparações entre os diversos países tem feito a ONU organismo internacional responsável pela elaboração do System of National Accounts (SNA) - divulgue, de tempos em tempos, um conjunto de recomendações, que a maior parte dos países procura seguir, a fim de tornar o mais homogêneo possível esse formato.

Dessa forma a partir de 1940, o Produto Interno Bruto (PIB) e Produto Nacional Bruto (PNB) passaram a ser considerados as principais variáveis econômicas para mensurar o movimento de uma economia em determinado período de tempo e, desde então se inicia um debate na academia sobre o conceito de desenvolvimento econômico. Discute-se se a concepção adequada do conceito de desenvolvimento deve ir além da acumulação de riqueza e do crescimento do PNB e, sobre quais outras variáveis deveriam ser consideradas para o adequado cômputo do PNB.

No bojo dessa discussão, ao longo do tempo, ganham ênfase economistas neoclássicos como Meade e Solow, autores de inspiração keynesiana como Harrod, Domar e Kaldor e, autores como Lewis, Hirschman, Myrdal e Nurkse que analisaram a realidade dos países subdesenvolvidos. No entanto, destaca-se Amartya Sen (1999), que em 1990 contribuiu para a formulação do conceito de Índice de Desenvolvimento Humano (IDH) - (SOUZA, 1999).

Para Sen:

(...) o crescimento econômico não pode sensatamente ser considerado um fim em si mesmo. O desenvolvimento tem de estar relacionado sobretudo com a melhora da vida que levamos e das liberdades que desfrutamos. Expandir as liberdades que temos razão para valorizar não só torna nossa vida mais rica e mais desimpedida, mas também permite que sejamos seres sociais mais completos... (2010, p.29)

À luz dessas considerações, para Sen o IDH é um índice sintético que compreende indicadores de três dimensões do desenvolvimento humano: saúde/longevidade, educação e renda. Baseando-se na ideia de que a qualidade de vida é dada pela liberdade que o indivíduo tem, entende-se que as pessoas precisam pelo menos ter a possibilidade de levar uma vida longa e saudável, acesso a conhecimento e a oportunidade de desfrutar de um padrão de vida digno. Deixando claro que o desenvolvimento humano significa alargar as escolhas das pessoas atribuindo maior destaque à riqueza de vidas humanas como saúde e educação e não considerar apenas os aspectos econômicos como nível de renda e acumulação de capital.

Nas palavras de Sen:

O desenvolvimento consiste na eliminação de privações de liberdade que limitam as escolhas e as oportunidades as pessoas de exercer ponderadamente sua condição de agente...O desenvolvimento, requer que se removam as principais fontes de privação da liberdade: pobreza e tirania, carência de oportunidades econômicas e destituição social sistêmica, negligencia das serviços públicos e intolerância ou interferência excessiva do Estado. (2010, p. 10-16) 
Enfim, ao longo do tempo o conceito de desenvolvimento se 'metamorfoseou', dessa forma os indicadores de desenvolvimento passaram a ser classificados em três categorias: econômicos, demográficos e socioculturais (Quadro 1).

Quadro 1: Classificação dos indicadores de desenvolvimento

\begin{tabular}{|c|c|}
\hline Indicadore & Variáveis \\
\hline \multirow{3}{*}{ Econômicos } & PIB per capita \\
& Repartição setorial da População Ativa \\
& Estrutura do Produto \\
& Consumo de energia/aço/habitantes \\
Indicadores do Comércio Externo
\end{tabular}

Fonte: Economiax (2016)

O Quadro 1 apresenta as variáveis e indicadores que geralmente são utilizados para analisar o desenvolvimento socioeconômico de uma região, considera-se a riqueza disponível, distribuição de pessoas no mercado de trabalho e condições de saúde a relação com o exterior. Considera-se ainda, outros condicionantes como número de televisores e automóveis a cada mil habitantes até o número consumido de proteínas por habitante. Isso mostra a complexidade de se estabelecer patamares de desenvolvimento para um país e mais ainda construir indicadores que abranjam ou pelo menos reflitam esses fatores.

\section{CONCEITUANDO AS PRINCIPAIS VARIÁVEIS QUE MEDEM A DESIGUALDADE SOCIAL}

De acordo com Jannuzzi (2012), os conceitos sobre indicadores sociais tiveram origem nas décadas de 1920 e 1930, no entanto ganharam destaque e robustez científica em meados da década de 1960, quando passou-se a estudar o impacto de políticas sociais nas sociedades desenvolvidas e 
subdesenvolvidas, haja vista que, o conceito de PIB per capita era insuficiente e, não conseguia captar o bem-estar social dos países.

Nesse contexto, instituições multilaterais como Organização para a Cooperação e Desenvolvimento Econômico (OCDE), Organização das Nações Unidas para Educação, Ciência e Cultura (UNESCO), Organização das Nações Unidas para Alimentação e Agricultura (FAO), Organização Internacional do Trabalho (OIT), Organização Mundial da Saúde (OMS), Fundo das Nações Unidas para a Infância (UNICEF), empreenderam em um esforço conceitual e metodológico para a construção de instrumentos de mensuração do bem-estar social, bem como a compreensão dos processos de mudanças sociais. Tal esforço culminou com a publicação dos livros Social Indicators Toward a Social Report, que representam o 'divisor de águas' na literatura sobre Sistemas de Indicadores Sociais (JANNUZZI, 2012).

Os indicadores sociais buscam quantificar a complexa realidade de uma localidade e, apesar de fornecerem bases para análises, por si só não são suficientes para descrever o nível de desenvolvimento de uma região, os indicadores encontrados devem ser analisados juntamente com arcabouço teórico adequado às especificidades locais. Haja vista que, os cientistas sociais deparamse com aspectos que não podem ser quantificados ou de difícil mensuração, que acabam não sendo expressos no índice. No entanto, ainda assim, os indicadores possibilitam mensurar as condições de vida e do bem-estar da população sendo utilizados, em grande medida, para a formulação de políticas públicas nas diferentes esferas do governo.

Cabe ressaltar que os indicadores são estimativas amostrais que se referem à população ou a grupos sócio demográficos específicos e, são expressos como taxas, proporções, médias, índices, distribuição por classes ou por cifras absolutas (JANNUZZI, 2012). Os indicadores sociais mais utilizados para medir a desigualdade e a qualidade de vida de uma região são a Renda per capita, Índice de Gini, IDH e a linha da pobreza (Quadro 2).

Quadro 2: Síntese dos conceitos dos principais indicadores sociais utilizados como medida de desigualdade social

\begin{tabular}{|c|c|c|}
\hline Indicadores & Conceito & Índices (variação) \\
\hline $\begin{array}{c}\text { Renda } p e r \\
\text { capita }\end{array}$ & $\begin{array}{c}\text { É o produto agregado de um país, } \\
\text { dividido pela população. Indica o } \\
\text { nível de renda da população. }\end{array}$ & $\begin{array}{c}\text { País em desenvolvimento - US\$ 10 mil } \\
\text { (renda média) }\end{array}$ \\
\hline Gini & $\begin{array}{c}\text { Mede o grau de concentração de } \\
\text { renda de uma determinada } \\
\text { localidade }\end{array}$ & $\begin{array}{c}\text { Varia de 0 a 1, quanto mais próximo de 1 pior } \\
\text { a concentração da renda. }\end{array}$ \\
\hline IDH & $\begin{array}{c}\text { Objetiva avaliar a qualidade de } \\
\text { vida nos países. }\end{array}$ & $\begin{array}{c}\text { Varia de } 0 \text { a } 1 . \\
0-0,5-\text { baixo desenvolvimento humano. } \\
0,5-0,8-\text { médio desenvolvimento humano. }\end{array}$ \\
\hline
\end{tabular}




\begin{tabular}{|c|c|c|}
\hline & $0,8-1-$ alto desenvolvimento humano. \\
\hline $\begin{array}{c}\text { Linha da } \\
\text { Pobreza }\end{array}$ & $\begin{array}{c}\text { Indica o mínimo de renda que um } \\
\text { habitante deve possuir para } \\
\text { satisfazer suas necessidades } \\
\text { básicas }\end{array}$ & US\$ 1,90 por dia, per capita. \\
\hline
\end{tabular}

Fonte: Elaborado pela autora com base nos dados do IPEA, PNUD e Atlas Brasil (2017)

Sendo assim, a renda per capita mostra o nível de renda da população de um país e por esse motivo é considerado um indicador qualitativamente superior ao PIB. De acordo com o Banco Mundial (2017) no ano de 2014 o PIB per capita do brasileiro foi cerca de US\$ 12 mil por ano, o que deveria indicar que a população brasileira possui condições mínimas de qualidade de vida, apesar de distante dos padrões praticados nos países desenvolvidos, haja vista que, nesse mesmo ano a renda per capta de um japonês foi de pouco mais de US\$ 38 mil.

Cabe salientar que, o indicador em questão é uma média e não informa sobre como a riqueza é verdadeiramente distribuída na sociedade, sendo assim a renda per capita é um indicador insuficiente para descrever o estágio de desenvolvimento socioeconômico de uma determinada localidade. Outro aspecto que deve ser considerado ao utilizar o índice de renda per capita é que para análises de comparações internacionais são necessários ajustes para refletir as diferenças do poder de compra em cada país e eliminar o efeito da variação brusca das taxas de câmbio (JANNUZZI, 2012).

O índice de Gini mede o grau de concentração de renda de uma localidade, para tanto divide a sociedade em cinco estratos onde cada estrato corresponde à $20 \%$ da população e, com base nisso mede a parcela da renda acumulada por cada um desses estratos. Esse índice varia de zero a um e, quanto mais próximo de um pior é a concentração de renda em determinada localidade (Gráfico 1).

Gráfico 1: Variação do Índice de Gini no Brasil - 1960 - 2014

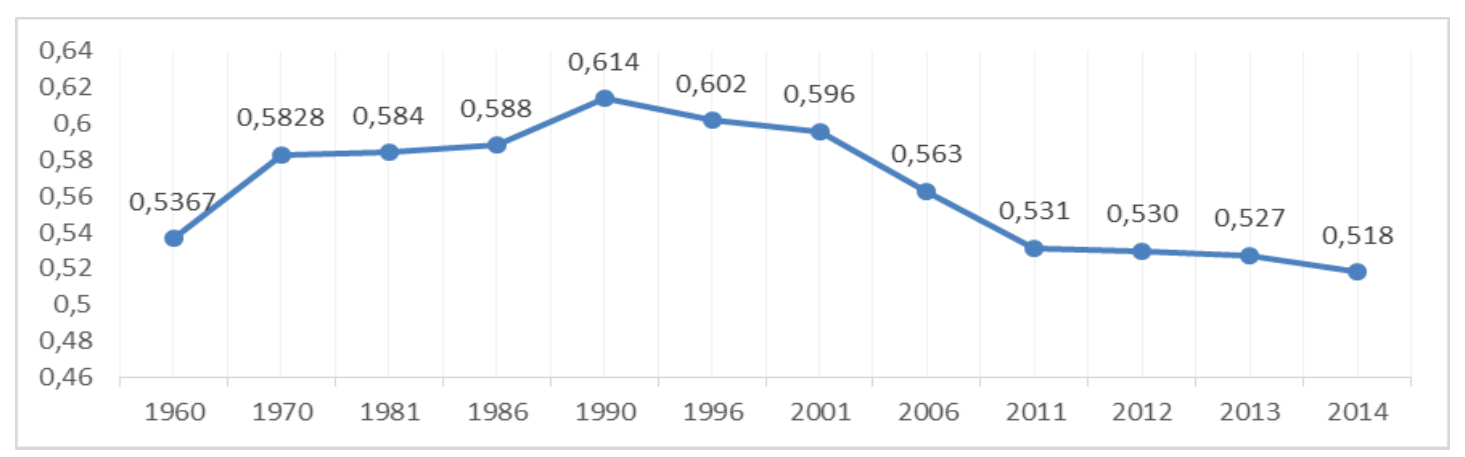

Fonte: Elaborado pela autora com base nos dados do IBGE e IPEA (2019) 
Nota-se no Gráfico 1 a enorme desigualdade social do país, expressa pelo índice de Gini, cabe salientar que o Brasil na década de 1990 possuía um dos piores índices de distribuição de renda do planeta (em torno de 0,61 ), disputando os últimos lugares no ranking mundial com países como Serra Leoa $(0,62)$ e Namíbia $(0,74)$.

Ainda de acordo com o Gráfico 1, percebe-se que na economia brasileira o processo de concentração da renda intensificou-se no período conhecido como 'milagre brasileiro', em meados da década de 1970, onde apesar do país apresentar elevadas taxas de crescimento do PIB (acima de $10 \%$ ao ano), a renda não era igualmente distribuída na sociedade, a justificativa ficou conhecida como a 'teoria do bolo', ou seja, o 'bolo', a riqueza produzida pelo país primeiro deveria crescer e depois ser repartida. De acordo com Paulani e Braga:

Para o discurso oficial da época, a concentração seria um mal necessário, na medida em que se constituía numa estratégia para elevar o nível de poupança e viabilizar os investimentos necessários ao processo de crescimento econômico. Após esse crescimento, todos estariam em melhor situação (...) a distribuição do 'bolo' acabou por não ocorrer, a despeito do crescimento verificado no produto per capita desde então. (2007, p.262)

De acordo com os dados do IBGE na década de 1960 os 40\% mais pobres da população detinham 11,2\% da renda e, na década de 1970 essa parcela da população reduziu sua participação na fatia do PIB para $9 \%$, ao passo que, os 5\% mais ricos aumentaram sua participação na fatia do PIB no mesmo período passando de 27,4\% na década de 1960 para 36,3\% da renda na década de 1970.

Enfim, nota-se no Gráfico 1 que o índice de Gini passou de 0,5367 em 1960 para 0,5828 em 1970 e atingiu um índice pior ainda em 1981 (0,584), evidenciando o aumento da desigualdade social no país. A década de 1980 ficou conhecida como a 'década perdida' devido ao fraco desempenho da economia brasileira aspecto que contribuiu para o aumento da concentração de renda no país, atingindo um índice de Gini de 0,614 em 1990.

Com relação ao IDH, é um índice idealizado pela Organização das Nações Unidas (ONU) e é publicado nos Relatórios do Desenvolvimento Humano do Programa das Nações Unidas para o Desenvolvimento (PNUD). O IDH é calculado desde o início da década de 1990 em mais de 170 países e, objetiva ponderar o índice renda per capita com indicadores sociais para avaliar a qualidade de vida nos países (PAULANI; BRAGA, 2007).

O IDH considera para o seu cálculo três indicadores: a) renda per capita (renda medida em US\$ para refletir a paridade do poder de comprar em nível internacional), b) saúde (índice de esperança de vida ao nascer) e, c) educação (média ponderado de outros dois indicadores, a taxa de alfabetização de adultos e a taxa de escolaridade nos níveis primário, secundário e superior). O IDH varia entre zero e um, se o índice ficar entre 0 e 0,5 indica baixo desenvolvimento de um país, se o 
índice ficar entre 0,5 e 0,8 indica médio desenvolvimento de um país e, se o índice ficar entre 0,8 e 1 indica alto desenvolvimento de um país.

Cabe salientar que o IDH representa um avanço na análise socioeconômica, no entanto não esgota a questão, haja vista que importantes variáveis sociais ainda permanecem excluídas de exames mais sofisticados como o índice de desemprego por exemplo, já que, quando o cidadão perde o emprego apenas as questões monetárias e materiais são levadas em conta, mas a insatisfação, a ociosidade e a falta de perspectiva? Como mesurar essas questões que estão diretamente relacionadas ao bem-estar?

No que tange aos indicadores socioeconômicos brasileiros Paulani; Braga (2007, p.276) afirmam que:

\begin{abstract}
...tem-se beneficiado enormemente dos trabalhos realizados pelo IPEA, em conjunto com o IBGE e a Fundação João Pinheiro, sob os auspícios do próprio PNUD. Essas pesquisas reunidas em relatórios como o Desenvolvimento Humano e Condições de Vida: Indicadores Brasileiros ou ainda o Atlas do Desenvolvimento Humano no Brasil, buscam adaptar a metodologia utilizada no cálculo do IDH..., além de calcular também o Índice de Desenvolvimento Humano Municipal (IDHM) e o Índice de Condições de Vida (ICV)...
\end{abstract}

No que tange a pobreza, cabe ressaltar que sua definição está relacionada ao desprovimento do bem-estar de parcela da população, ou seja, a escassa capacidade dos indivíduos de serem inseridos na sociedade, e isso em grande medida, pode ser mensurado por fatores como segurança, acesso a oportunidades, alimentação adequada e relacionamentos sociais (HAUGHTON; KHAN-DKER, 2009 apud IBGE, 2019).

Nesse sentido, a Linha de pobreza estabelece uma renda diária mínima para identificar o número de pessoas que vivem em situação de extrema pobreza, no entanto, na literatura não há um consenso quanto ao valor monetário dessa renda, já que, existem diferentes métodos de quantificar os rendimentos necessários para a aquisição de alimentos, despesas com habitação, transporte, entre outros fatores necessários para alcançar o bem-estar social.

Sendo assim, a definição do valor monetário depende dos custos da cesta básica que varia de região para região, nesse sentido o Banco Mundial, com base em diferentes estudos, em nível internacional, definiu valores em dólares por dia, para serem adotados pelos países, padronizou-se então o valor de US\$1,90 por dia, por pessoa. No caso específico do Brasil, devido a sua popularidade e simplicidade, a linha de pobreza é normalmente estabelecida em 1/2 salário mínimo da renda familiar per capita. Para recebimento de benefícios sociais o governo federal considera em situação de pobreza e extrema pobreza, famílias caracterizadas pela renda familiar mensal per capita entre $\mathrm{R} \$ 145,00$ a $\mathrm{R} \$ 420$ e de $\mathrm{R} \$ 145,00$, respectivamente (IBGE, 2019). 


\section{RESULTADOS ALCANÇADOS}

Entre 2000 e 2014 a renda média do Brasil aumentou, haja vista que, o PIB per capita passou de US\$ 3.739,12 para cerca de US\$ 12 mil, esse fator foi acompanhado de uma significativa redução de pessoas em situação de extrema pobreza, que passaram de 15,19\% da população em 2001, para 4,2\% em 2014 (Quadro 3).

Quadro 3: Comportamento dos principais indicadores socioeconômicos no Brasil entre de 2000 e 2014.

\begin{tabular}{|l|c|c|c|c|}
\hline \multicolumn{1}{|c|}{ Ano } & 2000 & 2004 & 2014 & $\begin{array}{c}\text { Variação entre } \\
2000-2014\end{array}$ \\
\cline { 1 - 3 } \multicolumn{1}{|c|}{ Indicador } \\
\cline { 1 - 2 }$\left(\begin{array}{l}\text { PIB per capita } \\
\text { PIB per capita } \\
(\mathrm{R} \$)\end{array}\right.$ & $3.739,12$ & $3.623,05$ & $12.026,62$ & $221.6 \%$ \\
\hline Índice de Gini & $0.596 *$ & 0.572 & 0.518 & $-13.1 \%$ \\
\hline IDH & 0.683 & 0.792 & 0.755 & $10.5 \%$ \\
\hline $\begin{array}{l}\text { Linha da } \\
\text { pobreza }\end{array}$ & $15.19 \% *$ & $13.22 \%$ & $4.20 \%$ & $-72.4 \%$ \\
\hline
\end{tabular}

Fonte: Elaborado pela autora com base nos do IPEADATA, IBGE e Banco Mundial.

*Dados referentes do ano 2001.

Nota-se no Quadro 3 que, o PIB per capita no Brasil no período entre 2000 e 2004 teve uma evolução pouco significativa, já no período de 2004 para 2014 verificou-se uma acentuada expansão da renda, isso em grande medida pode ser explicado, pela estabilidade dos preços, pelo aumento real do salário mínimo, pela maior formalização no mercado de trabalho e, pelo aumento dos gastos sociais em educação e em programas de transferência direta de recursos. No entanto cabe salientar que:

(...) persistem desafios estruturais ligados à redistribuição de renda e riqueza no País, como o estabelecimento de uma política tributária justa, a melhoria da qualidade de serviços públicos, a reversão da concentração fundiária, além da inclusão educacional de adolescentes e jovens em idade universitária (sobretudo jovens negros) - para citar alguns (OXFAM, 2017, p.12).

No que tange a questão fundiária, ressalta-se que no Brasil, o cumprimento da função social da terra ${ }^{1}$ é condição basilar para a manutenção do direito à propriedade privada, no entanto, $\mathrm{o}$ execução desse princípio não é respeitado pelos latifundiários, haja vista que, em tese esse princípio estabelece que a propriedade privada da terra deve cumprir, três requisitos básicos, a saber: a) uso

\footnotetext{
${ }^{1}$ É relativa ao uso da terra, e não ao direito legal, nesse contexto, a Constituição Federal, faz a terra cumprir sua função social, porque a ocupação que não a cumpre, por mais rentável que seja, incorre em ilegalidade (Melo, 2019).
} 
racional e adequado dos recursos naturais disponíveis; b) preservar o meio ambiente e; c) cumprir a legislação trabalhista e promover o bem-estar dos trabalhadores (MELO, 2019).

No Brasil os latifundiários, de maneira geral, mantêm terras improdutivas, não preservam adequadamente os recursos naturais e o meio ambiente e, não favorecem o bem-estar dos trabalhadores rurais. Dessa forma, nota-se que, o não cumprimento da função social da terra, fortalece o latifúndio em detrimento da realização da Reforma Agrária e, consequentemente tem-se o aumento da pobreza, do desemprego e a redução da renda, enfim, tem-se a continuidade da desigualdade no campo.

Cabe ressaltar que após o golpe parlamentar ocorrido no país em 2016, a Bancada Ruralista ampliou sua importância política no Congresso Nacional, fortalecendo o latifúndio e mantendo a reforma agrária estagnada. Nesse contexto o Ministério do Desenvolvimento Agrário (MDA) foi extinto, e tem-se verificado a perda de direitos conquistados por trabalhadores do campo, por meio dos movimentos sociais organizados e também por meio das políticas públicas realizadas nos governos do Partido dos Trabalhadores. Além das perdas sociais, verifica-se a intensificação da criminalização de movimentos sócio territoriais na tentativa de invisibilizar a luta pelo direito a propriedade da terra de camponeses, indígenas e quilombolas (MITIDIERO JUNIOR, M. A.; FELICIANO, C. A., 2018; MELO, 2019).

Ainda de acordo com o Quadro 3 observa-se que o coeficiente de Gini apresentou redução no período analisado, nos quatro primeiros anos, uma redução de $4 \%$ e, nos dez anos seguintes, o coeficiente diminuiu 9,44\%. Com relação ao IDH, verifica-se um aumento desse índice, ou seja, ocorreram melhorias não apenas quantitativas como aumento da renda per capita mas, também melhorias qualitativas expressas nesse índice como aumento do número de matrículas em todos os níveis de escolaridade bem como melhoria nas condições de vida da população que culminaram em uma maior longevidade.

Enfim, a redução da desigualdade de renda e a melhoria da qualidade de vida da população brasileira, mensuradas pelo índice de Gini e pelo IDH, implica em menores taxas de mortalidade infantil e maior a expectativa de vida ao nascer, tais aspectos podem ser resultado do aumento do acesso a direitos básicos e maior oferta de serviços essenciais como acesso à água encanada e energia elétrica bem como assistência médica.

No Gráfico 2, nota-se que no período analisado a taxa de mortalidade infantil reduziu de 29 bebês com menos de um ano de idade por mil nascidos vivos em 2000, para 17, 22 em 2010 e, no ano de 2018 esse índice foi de 12,35. Em nível mundial esse índice está abaixo do índice verificado em países Somália e Paquistão, onde a mortalidade foi respectivamente 95 e 52 bebês com menos de um ano de idade por mil nascidos vivos em 2017, no entanto o índice de mortalidade 
infantil brasileira ainda é superior ao encontrado em países desenvolvidos como Alemanha e Itália, que possuem um índice de mortalidade 3 bebês por mil nascidos vivos no de 2017 (Indexmund, 2019).

Gráfico 2: Esperança de vida ao nascer e Taxa de mortalidade infantil no Brasil entre 2000-2018

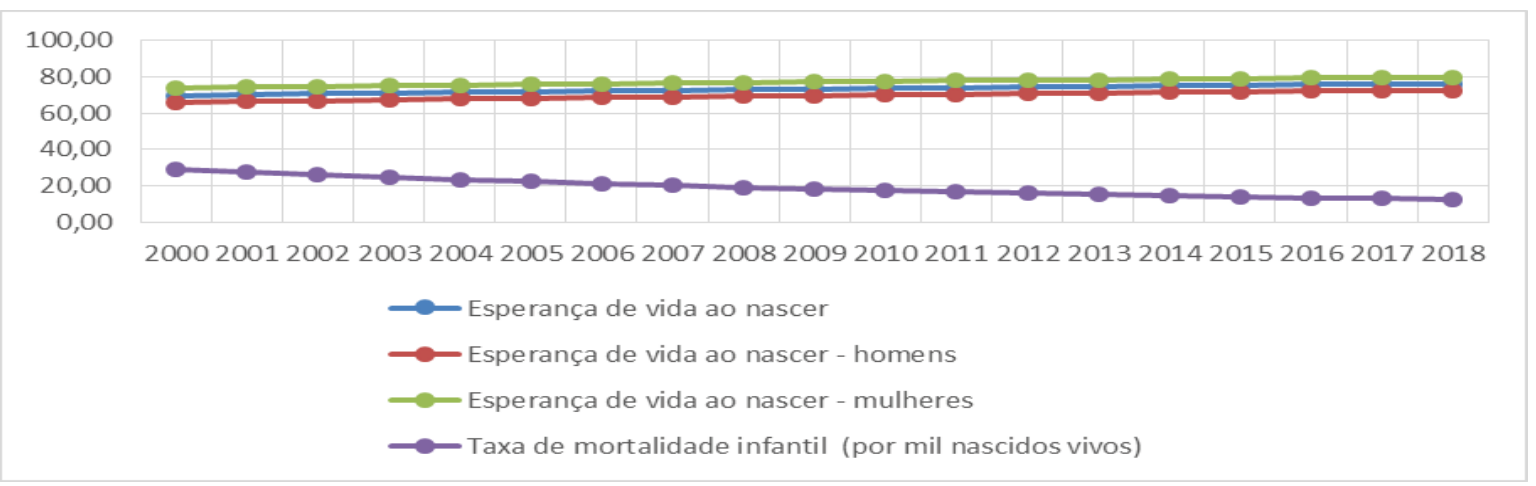

Fonte: Elaborado pela autora com base nos do IBGE (2019).

Ainda de acordo com o Gráfico 2, no que tange à expectativa de vida ao nascer, percebe-se que que entre os anos 2000 e 2018 essa variável aumentou em média 6 anos, passando de 70 para 76 anos, no entanto, em 2018 a esperança de vida ao nascer das mulheres era de cerca de 80 anos e dos homens quase 73 anos. Cabe ressaltar que historicamente e mundialmente as mulheres vivem mais tempo que os homens, em grande medida isso pode ser explicado pelas mortes associadas às causas externas ou não naturais que afligem adultos jovens do sexo masculino que incluem os homicídios, suicídios, acidentes de trânsito, afogamentos, quedas acidentais entre outras (IBGE, 2019).

O Gráfico 3, mostra que o número de pessoas pobres e extremamente pobres no Brasil reduziu significativamente entre o ano 2001 e 2014. Em 2001 haviam cerca de 59 milhões de brasileiros pobres e, 25,5 milhões vivendo na extrema pobreza, em 2014 verificou-se uma redução do número de brasileiros considerados pobres para 25,8 milhões e, a população vivendo em extrema pobreza diminuiu para 8,2 milhões de pessoas. 
Gráfico 3: número de pessoa pobres e extremamente pobres no Brasil entre 2001-2014

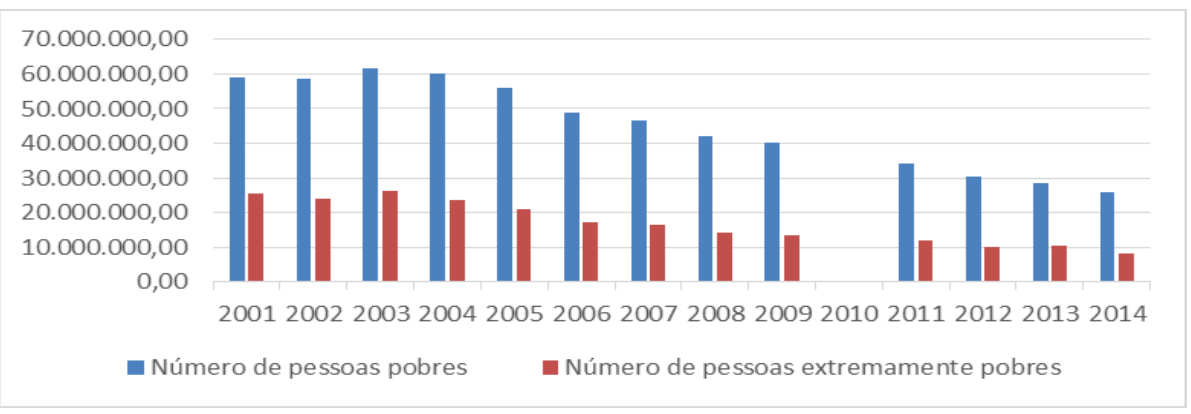

Fonte: Elaborado pela autora com base nos do IPEADATA (2019)

À luz dessas considerações Oxfam (2017), destaca que o aumento da renda da população de baixa renda não tem sido suficiente para reduzir a enorme desigualdade que persiste na sociedade brasileira, visto que entre 2001 e 2015 , os $10 \%$ mais ricos se apropriaram de $61 \%$ do crescimento econômico, enquanto a fatia dos $50 \%$ mais pobres apoderaram-se de $18 \%$ a riqueza gerada. Neste mesmo período, a concentração de renda no $1 \%$ se manteve estável, no patamar de 22 a 25\%, bem como a participação na renda dos $40 \%$ mais pobres da população (Gráfico 4).

Gráfico 4: Desigualdades medidas pelos índices de Gini, pela proporção de domicílios em situação de pobreza, pela proporção da renda nacional recebida pelos $40 \%$ mais pobres e pelo $1 \%$ mais rico 1976-2015.

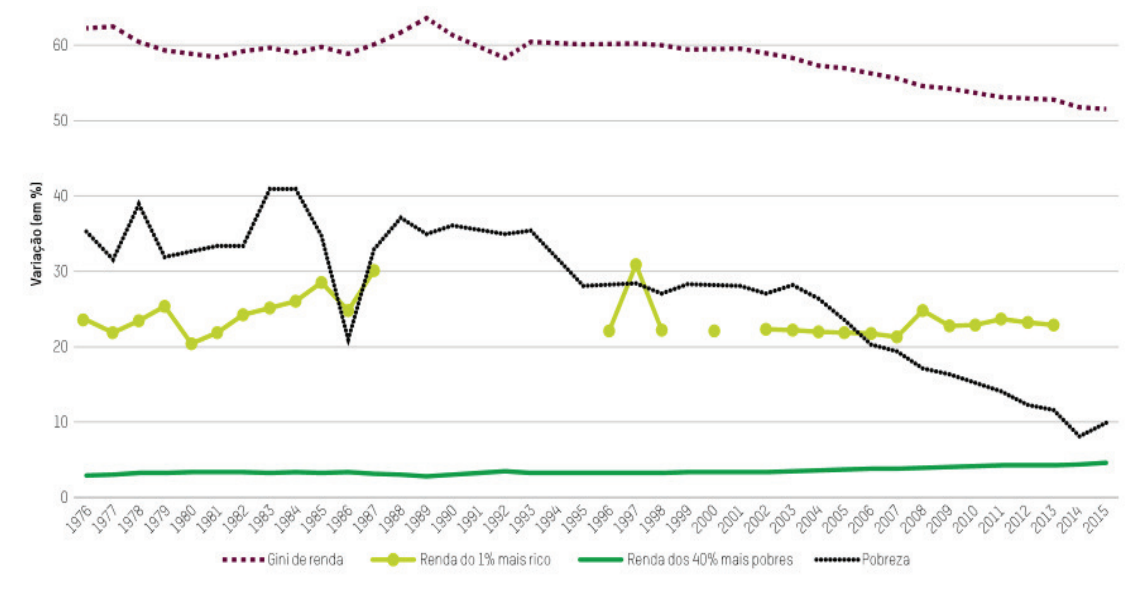

Fonte: Oxfam (2017) apud Ipeadata 2014; Pnud 2017; Souza, P. H. 2016

Enfim, de acordo com o relatório do Oxfam (2017, p. 18), a melhoria dos indicadores sociais, entre 2000 e 2015, são reflexos de mudanças estruturais na sociedade brasileira como “...crescimento econômico, alterações demográficas e migrações, inclusão da mulher no mercado de trabalho, políticas federais de redistribuição de recursos para a oferta de infraestrutura básica e a 
transição de um regime ditatorial para a democracia". Cabe salientar que essa conjuntura, apesar de manter o status quo, contribuiu para a retirada do Brasil do mapa da fome ${ }^{2}$ da ONU, em 2015.

Apesar da melhoria dos indicares socioeconômicas apontados ao longo do texto, após o golpe parlamentar de 2016, verifica-se que a concentração de renda e a desigualdade social voltaram a aumentar, isso pode ser mensurado pela volta do país ao mapa da fome da ONU em 2017, e o aumento do número de pessoas vivendo em situação de extrema pobreza. Em 2018, o IBGE registrou o aumento do número de pessoas nessa situação, 13,5 milhões de brasileiros, ou seja, são pessoas que sobrevivem com renda mensal per capita inferior a R\$145, ou U\$S 1,90 por dia (IBGE, 2019).

Com relação a renda, nota-se no Gráfico 5, que até biênio 2012/2013 a média dos rendimentos dos 40\% mais pobres da sociedade brasileira e dos 10\% mais ricos cresciam em termos reais, cabe salientar que considerando a média da base da distribuição, os $40 \%$ com menor rendimento tinham ganhos maiores que os rendimentos médios da parcela da população que obtinham os $10 \%$ de maiores rendimentos.

Gráfico 5: Taxa de variação anuais dos rendimentos médios, por classes de rendimento habitual de todos os trabalhadores no Brasil - 2012/2018

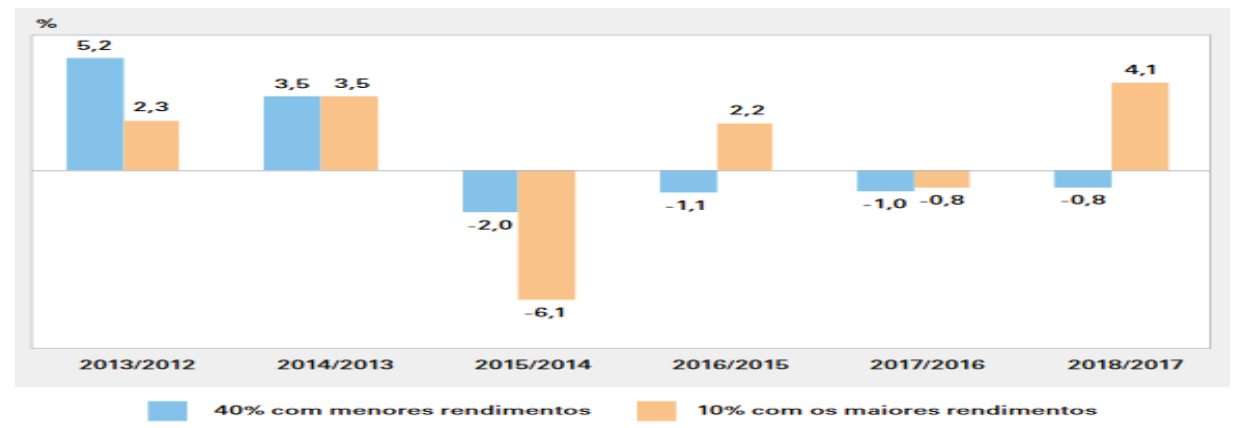

Fonte: IBGE, 2019

Ainda de acordo com o Gráfico 5 percebe-se que, em 2014, as rendas dos trabalhadores de ambos os grupos caíram e, a partir de 2015 nota-se que a população com os menores salários passa o obter perdas reais de rendimento, enquanto os $10 \%$ com maiores rendimentos voltam a ter ganhos reais. Em 2018, acentua-se desigualdade entre os trabalhadores brasileiros, isso em certa medida pode ser explicado, pela ausência de aumento real do salário mínimo e pelo aumento do desemprego gerado pelo baixo crescimento econômico.

\footnotetext{
2 O Mapa da Fome no mundo é divulgado periodicamente, desde 1990, pela Organização das Nações Unidas para Agricultura e Alimentação- FAO. O mapa indica os países onde parte significativa da população está ingerindo quantidades diária de calorias abaixo do padronizado internacionalmente (FAO, 2019).
} 


\section{CONSIDERAÇÕES FINAIS:}

Entre os anos 2000 e 2015 verifica-se a melhoria dos indicadores sociais e econômicos no Brasil, em certa medida isso é reflexo, das políticas públicas adotadas nos governos do Partido dos Trabalhadores, haja vista que essas políticas vislumbraram por um lado a redução da pobreza por meio de programas de transferência de renda, ao acesso a direitos básicos e maior oferta de serviços essenciais como água encanada, energia elétrica bem como assistência médica, e por outro lado, buscavam impulsionar o crescimento econômico e a geração de empregos formais.

Nesse período, o país além de crescer economicamente, conseguiu reduzir a desigualdade social e permitiu que milhares de pessoas deixassem a pobreza extrema. Dessa forma, tendo em mente que desenvolvimento humano significa alargar as escolhas humanas atribuindo maior destaque à riqueza das vidas e não simplesmente à riqueza das economias, constatou-se o desenvolvimento econômico no período analisado, juntamente com a redução da desigualdade social, favoreceu a melhoria da condição de vida da população brasileira.

No entanto, cabe salientar que apesar da melhoria da conjuntura socioeconômica ter beneficiado fortemente as classes menos favorecidas monetariamente, o país manteve o status quo, no que tange a enorme desigualdade social que ainda persiste na sociedade brasileira. Ressalta-se ainda que, após o golpe parlamentar de 2016 que, interrompeu o mandato da Presidente Dilma Rousseff e, comprometeu a democracia brasileira, muitas conquistas sociais foram perdidas e houve a piora dos indicadores sociais como o aumento do número e pessoas vivendo em situação de extrema pobreza, e a volta do Brasil do mapa da fome da ONU.

\section{REFERÊNCIAS:}

BARROS, Alexandre Rands. Desigualdades regionais no Brasil: natureza e causas. Rio de Janeiro: Elsevier, 2011.

IPEA. Cartilha vozes da classe média, 2012. Disponível em: http://www.ipea.gov.br/agencia/images/stories/PDFs/comunicado/120925_comunicadodoipea155 v5.pdf. Acesso em: 22 mar. 17.

ECONOMIAX. Crescimento e desenvolvimento econômico. Disponível em: ttp://economiax.blogspot.com.br/2009/10/crescimento-e-desenvolvimento economico.html. Acesso em: abr. 2016.

FAO. Organização das Nações Unidas para Agricultura e Alimentação. Disponível em: http://www.fao.org/brasil/fao-no-brasil/brasil-em-resumo/pt/. Acesso em: nov. 2019.

IBGE. Instituto Brasileiro de Geografia e Estatística. Síntese de indicadores sociais: uma análise das condições de vida da população brasileira. Coordenação de população e indicadores sociais. Rio de Janeiro: IBGE, 2019. 
IBGE. Instituto Brasileiro de Geografia e Estatística. Disponível em: https://www.ibge.gov.br/. Acesso em: nov. 2019.

Indexmund. Mapa comparativo entre países. Disponível em: https://www.indexmundi.com/map/?v=29\&l=pt. Acesso em: nov. 2019.

KEYNES, John Maynard. A teoria geral do emprego, do juro e da moeda: inflação e deflação. 2. ed. São Paulo: Nova Cultural, 1985. (Os economistas)

NERI, Marcelo Côrtes; SOUZA, Pedro Herculano Cavalcanti Ferreira de. (Baseado). A Década Inclusiva (2001-2011): desigualdade, pobreza e políticas de renda. IPEA. 2012.

MELO, Thiago da Silva. Latifúndio e descumprimento da função social da terra no Brasil. Caminhos de Geografia. Uberlândia, v. 20, n. 71, p.137-151, set. 2019.

MITIDIERO JUNIOR, M. A.; FELICIANO, C. A. A VIOLÊNCIA NO CAMPO BRASILEIRO EM TEMPOS DE GOLPE E A ACUMULAÇÃO PRIMITIVA DE CAPITAL. OKARA: Geografia em debate, v.12, n.2, p. 220-246, 2018.

OXFAN. A distância que nos une: um relatório das desigualdades brasileiras. 2017.

PAULANI, Leda Maria; BRAGA, Márcio Bibik. A nova contabilidade social: uma introdução à macroeconomia. 3. ed. São Paulo: Saraiva, 2007.

SEN, Amartya. Desenvolvimento como liberdade. São Paulo: Companhia das letras, 2010.

SOUSA, Jessé. Os batalhadores brasileiros: nova classe média ou nova classe trabalhadora? 2. ed. Belo Horizonte: UFMG, 2012.

SOUSA, Nilson Araújo. Economia brasileira contemporânea: de Getúlio a Lula. 2. ed. São Paulo: Atlas, 2008.

\section{AUTORA:}

Paula Margarita Andrea Cares Bustamante

Professora da Universidade Estadual de Montes Claros

E-mail: paulacares@yahoo.com.br

Recebido em 15/07/2019.

Aceito em 27/11/2019. 